\title{
Construyendo el pasado, reproduciendo el presente: identidad y arqueología en las recreaciones históricas de indígenas contra romanos en el Noroeste de España
}

\author{
Building the Past, Reproducing the Present: Identity \\ and Archaeology in the Historic Recreations of Indigenous \\ Peoples versus Romans in Northwestern Spain
}

\author{
Pablo Alonso González \\ University of Cambridge \\ David González Álvarez \\ Universidad Complutense de Madrid
}

\section{RESUMEN}

El desarrollo del "Estado de las Autonomías" tras el restablecimiento de la democracia en España ha potenciado la proliferación de narrativas sobre el pasado que buscan legitimar las nuevas estructuras administrativas y homogeneizar sus formaciones identitarias. Esto se solapa con un creciente interés de la ciudadanía por el pasado y su escenificación en la esfera pública a través de recreaciones históricas. El estudio analiza tres recreaciones históricas en el noroeste español y su vinculación con discursos constructores de alteridad identitaria a nivel sociopolítico. Igualmente, estudia los intercambios y mediaciones producidas entre el conocimiento académico y su recepción por parte del público, demostrando cómo ciertas cuestiones sociopolíticas se ven reflejadas en eventos aparentemente neutrales.

Palabras clave: Recreaciones históricas, Memoria, Construcción identitaria, Estado de las Autonomías, Patrimonio cultural, Arqueología pública.

\section{SUMMARY}

The development of a quasi-federal administrative framework based on Regional Governments (Comunidades Autónomas) after the restoration of democracy in Spain, has led to the proliferation of narratives about the past that seek to legitimize the new administrative structures and homogenize their identity formations so as to reinforce their internal social cohesion. This process is paralleled by a growing public interest in the past and its staging through historical reenactments. The paper analyzes the connection between both processes in three historical recreations in northwest Spain. Also, it considers the reenactments as spaces where academic knowledge reaches and is assumed in multiple ways by the public. Despite the events seem to be largely neutral at first sight, our research suggests that they are actually highly ideologically charged.

Key words: Historic Reenactments, Memory, Identity Building, Spanish Administrative Framework, Cultural Heritage, Public Archaeology. 


\section{INTRODUCCIÓN: LAS FIESTAS DE RECREACIÓN HISTÓRICA}

Cornelius Holtorf afirmó recientemente, refiriéndose al pasado, que «las percepciones de muchos importan tanto, o más, que el conocimiento factual de unos pocos" (2005: 8). Más allá de los debates sobre el pasado, confinados a nuestra torre de marfil académica, en los últimos años asistimos a una explosión en la construcción social de imágenes y representaciones culturales al respecto. Las recreaciones históricas son lugares especialmente apropiados para analizar cómo se construyen las percepciones de "los muchos" en sociedad.

En las dos últimas décadas se ha producido un auge de las fiestas de recreación histórica en España. Estos eventos no sólo han aumentado en número, sino que su celebración ha ganado en visibilización y en participación ciudadana. Su creciente audiencia es consecuencia del apoyo y difusión dado por los medios de comunicación y las instituciones públicas, que han comenzado a reconocer la gran proyección de estas fiestas otorgándoles en muchos casos declaraciones de interés turístico. Muchos de estos festivales se han complicado, con programas amplios y diversos, aumentando y diversificando sus fuentes de financiación. Destacados ejemplos de este tipo de eventos de recreación histórica son el festival romano "Tarraco Viva" en Tarragona o la fiesta "Carthagineses y Romanos" en Cartagena. En el Noroeste español, área geográfica en la que se sitúan los casos de estudio analizados, también prolifera este tipo de fiestas, con ejemplos como la "Fiesta Medieval de la Arribada" en Baiona (Pontevedra) o la recreación histórica "Toma de Astorga 1812" en dicha ciudad leonesa.

En particular, hemos tomado como casos de estudio una serie de eventos que rememoran el contacto entre los pueblos prerromanos que poblaban este área -cántabros, astures, galaicos- y Roma, que desembocaría en enfrentamiento en el transcurso de las Guerras Cántabras (29-19 a.C.) (Peralta Labrador 2009). Los ejemplos ya consolidados de este tipo de fiestas servirán de base a nuestra investigación: el festival "Guerras Cántabras" (12 ediciones) en Los Corrales de Buelna (Cantabria), las "Fiestas de Astures y Romanos" (8 ediciones) en Astorga (León) y el "Festival Astur-Romano de La Carisa" en Carabanzo (Asturias) (7 ediciones) (Fig.1). Al mismo tiempo, nuevos eventos continúan surgiendo en nuestro ámbito de estudio, como la fiesta "Ludus Bergidum Flavium" en Cacabelos (León), "Arde Lucus" en Lugo o el "Mercado Asturromano" de Santibañez de Vidriales (Zamora).

En este tipo de fiestas, la población local y grupos visitantes se visten de época y escenifican una serie de actos que recrean acontecimientos históricos, fundamentalmente batallas, ceremonias rituales y desfiles. En los casos más desarrollados de Astorga y Los Corrales de Buelna, se levantan cabañas indígenas o tiendas romanas que sirven como espacios de representación y de socialización para los propios participantes y el público visitante.

El afán de recrear fielmente los sucesos históricos a lo largo de las celebraciones se mezcla con la búsqueda de entretenimiento y el ambiente festivo. Con tal objetivo, la puesta en escena de la narración histórica suele partir de los relatos clásicos que nos describen la conquista de los pueblos del norte (Schulten 1943) y de la obra de autores como Plinio o Estrabón, que describen a los montañeses norteños y sus salvajes costumbres. Sin embargo, las claras motivaciones políticas de estos autores 

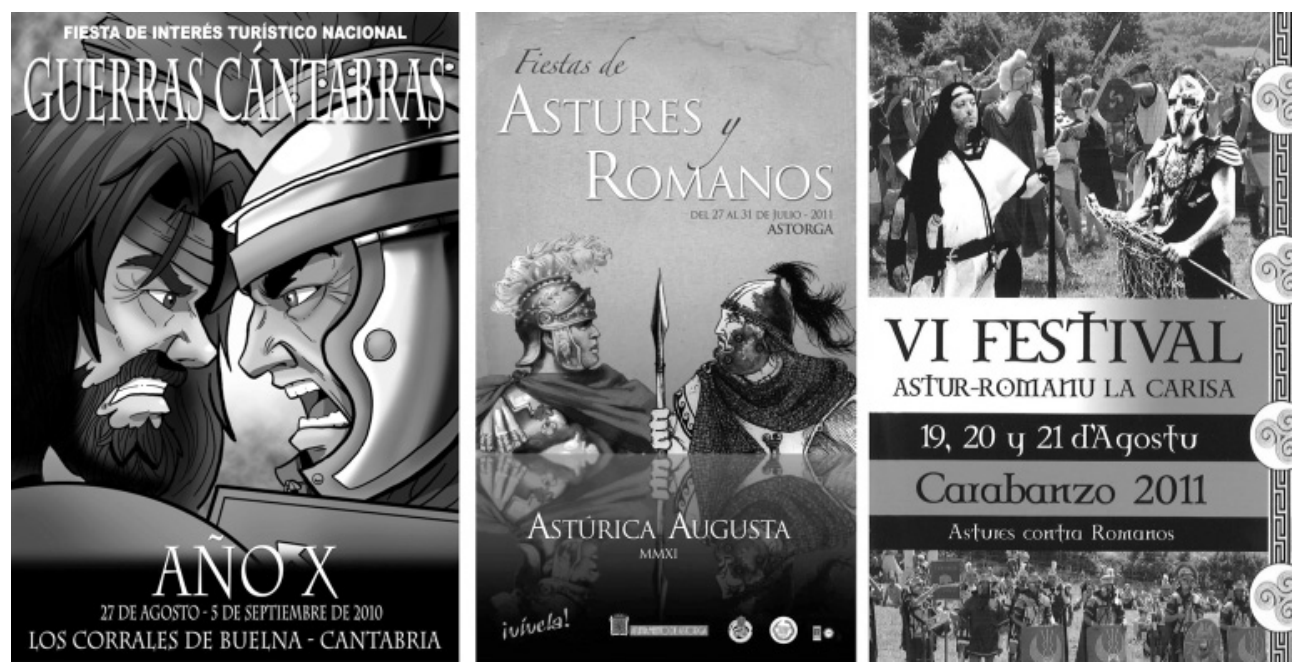

Figura 1.-Carteles de ediciones recientes de las recreaciones históricas estudiadas.

al servicio de Roma, o su marcado sesgo etnocéntrico (Salinas de Frías 1998, 2011), no son objeto de consideración. Más aún, la representación teatralizada de los hechos históricos y el tono melodramático se unen al ambiente festivo generalizado, todo lo cual contribuye a simplificar y a estereotipar los actos escenificados y los protagonistas de las Guerras Cántabras.

En estas fiestas resulta difícil -además de metodológicamente inadecuado- diferenciar motivaciones culturales y festivas. El guión de estos eventos mezcla acontecimientos históricos con banquetes, bailes y vida nocturna. También se organizan mercados de época, competiciones deportivas en las que los participantes caracterizados como indígenas rivalizan con los romanos, juegos infantiles o conciertos, habitualmente de música folk. Además, suelen programarse actividades culturales, como encuentros, conferencias o exposiciones sobre los acontecimientos y el período histórico en el que se encuadra el evento de recreación. Generalmente están organizadas por una asociación cultural local, con el apoyo de ayuntamientos e instituciones regionales, además del comercio local. En general, no muestran rasgos muy distintos a otros ejemplos europeos de reenactment (Agnew 2007; Appleby 2005; Cook 2004; Gapps 2003).

En España, los eventos de recreación histórica apenas han centrado la atención de las ciencias sociales, predominando acercamientos exploratorios que reconocen su interés como escenarios sociales a examinar pero sin profundizar en exceso. Podemos sintetizarlos en tres grupos:

En primer lugar, existen trabajos que tratan de recomponer el origen y genealogía histórica de este tipo de celebraciones (Brisset Martín 1997, 2001), realizando categorizaciones de los eventos en función de su estructura y contenidos.

Otros autores -fundamentalmente sociólogos o especialistas en patrimonio- buscan desvelar los intereses económicos subyacentes y que funcionan como motores de las fiestas de recreación histórica (Pena Castro 2004; Rojas Rabaneda 2011). Así, 
entienden que son recursos para potenciar el turismo y amplificar el consumo. Pena Castro observa cómo en la "Feira Medieval de Noia" (A Coruña) "a este afán económico se le busca una coartada identitaria de exaltación de la tradición histórica de la villa, que fomentaría los lazos del presente con el pasado en una reafirmación constitutiva de la comunidad" (2004: 85). De este modo, la potenciación identitaria y el refuerzo del sentimiento de pertenencia a una comunidad a través de discursos históricos se situarían siempre por detrás de tales intereses económicos. A nuestro juicio, estos trabajos mantienen un nivel de análisis excesivamente centrado en el ámbito económico y en los discursos racionales o conscientes de los actores sociales, dejando de lado cuestiones estructurales ${ }^{1}$. No puede minusvalorarse el actual interés popular en estas cuestiones identitarias, puesto que de no ser así, estos festivales no revestirían un poder atractivo de público tan importante. De hecho, la evolución de celebraciones como las "Fiestas de Astures y Romanos" de Astorga no puede desligarse de ciertos acontecimientos políticos a escala local que subrayan la fuerza de las fiestas de recreación histórica como escenarios destacados de reproducción de ideologías contemporáneas a través de la evocación y naturalización de identidades pretéritas.

Por último, otro grupo de investigadores -fundamentalmente arqueólogos- ha centrado sus análisis en el interés del público por estos eventos. Así, consideran las recreaciones históricas como herramientas útiles en la difusión de temas históricos o sitios arqueológicos (Burillo Mozota 2005: 25-27; Colomer 2002; Jimeno Martínez 2000; Ruiz Zapatero 2005). Esta observación es incontestable, y basta con acudir a los actos culturales paralelos a las fiestas de recreación para advertir el interés que despiertan las charlas y exposiciones. Ahora bien, escasean las reflexiones profundas acerca de la "calidad", proveniencia, formas de transmisión y consumo de esos discursos. No nos referimos a su exactitud en términos históricos o a la propagación de equívocos o generalizaciones, sino al esencialismo y a la simplificación imperantes (Marín Suárez et al. 2012).

\section{OBJETIVOS}

A partir de las aproximaciones previas, nuestro estudio analiza, en primer lugar, la repercusión de los discursos sobre el pasado que se construyen durante estas fiestas en las políticas locales de gestión arqueológica y patrimonial.

En segundo lugar, investigamos cómo las fiestas de recreación histórica se constituyen en formas prioritarias de normalización y transmisión de ideologías contemporáneas que, proyectadas al pasado, terminan por naturalizar actitudes, identidades y agendas políticas del presente (Stocking Jr. 1965).

Igualmente, constituyen espacios para la adquisición y transmisión de conocimiento histórico, donde el público activamente construye y recrea el pasado. Así, explora-

\footnotetext{
${ }^{1}$ En este sentido, es común que se critiquen o deconstruyan discursos políticos en los que se afirma que las recreaciones se realizan para "reforzar la identidad de la comunidad", cuando resulta evidente que existen múltiples y variados intereses que van más allá del "discurso políticamente correcto" que se hace circular en la esfera pública.
} 
mos el papel que juega la materialidad en la reproducción, negociación y construcción de discursos históricos "desde abajo", ya que la iniciativa ciudadana es el motor de estos eventos, siendo testimonial la participación de académicos o gestores patrimoniales. Pese a que se ha señalado la importancia de la contribución de estos eventos al incremento del interés público por el pasado, no se han analizado las formas a través de las cuales el conocimiento se adquiere, se negocia, se reproduce y, finalmente, se transmite entre los participantes en las fiestas. Del mismo modo, no se han valorado en profundidad las formas en las que este conocimiento se difunde a un público más amplio ni su imbricación con ideologías y problemas contemporáneos.

Por último, hemos estudiado la conexión entre estos eventos y procesos sociopolíticos contemporáneos, fundamentalmente nacionalismos y procesos de construcción identitaria. Las fiestas de recreación histórica generan contextos festivos donde el público toma contacto con acontecimientos históricos que, por regla general, son hitos destacados en la historia (y épica) regional. Esto se vincula con los múltiples procesos de "invención de la tradición" (Hobsbawn y Ranger 1992) desencadenados en España tras la consolidación del Estado de las Autonomías. Así, consideramos que el auge de estas fiestas se relaciona directamente con el nuevo contexto sociopolítico surgido con el modelo territorial autonómico. En este sentido, desarrollamos los trabajos que han relacionado arqueología y nacionalismo, tanto español-centralista durante la dictadura franquista (Díaz-Andreu 1993, 2003; Ruiz Zapatero 2003; Tejerizo García 2012; Viejo-Rose 2011), como autonómico-centrífugo a partir de la transición (Díaz-Andreu 1995; Díaz Santana 2002; Marín Suárez 2005; Marín Suárez et al. 2012; Ruiz Zapatero 2006).

\section{MARCO TEÓRICO Y METODOLÓGICO}

Nuestro trabajo se sitúa a mitad de camino entre las investigaciones antropológicas sobre procesos de patrimonialización (Geertz 1997; Rowlands y De Jong 2007) y la arqueología y estudios de cultura material (Castañeda 2008; Meskell 2012; Miller 1998). Igualmente, pretendemos realizar una aportación al ámbito de lo que se ha llamado la Arqueología Pública (Almansa Sánchez 2011; Merriman 2004; Moshenska 2009; Schadla-Hall 1999); y darle un giro materialista a las investigaciones llevadas a cabo hasta el momento sobre recreaciones históricas (Agnew 2007; Cook 2004; Gapps 2003). Consideramos fundamental la superación de la dicotomía analítica y conceptual entre cuestiones "identitarias" y "económicas" (García Canclini 1982). Partimos de la idea de que ambas esferas se co-constituyen relacionalmente y encuentran intrínsecamente unidas (Comaroff y Comaroff 2009: 24), proporcionando la identidad valor económico (Rullani 2006), y el poder económico la capacidad de sancionar y construir identidades hegemónicas (Thrift 2006). La investigación procura suplir la falta de aproximaciones en las que "se integren situaciones políticas y económicas con análisis contextuales bien documentados de relaciones sociales" (Hall 2007: 14), una situación que se acentúa en el contexto español (Sánchez Carretero y Ortiz García 2008). Así, hemos analizado la construcción de significados y sentidos a partir del estudio materialista de "Cómo los cuerpos son inscritos y marcados" (Bogard 1998: 54) de ciertas formas y no de otras, y cómo las estructuras sociales se reflejan en representaciones 
culturales que segmentan, canalizan y reordenan lo social. Realizamos pues un análisis de la economía política de la producción cultural, donde la recreación histórica es entendida como un evento reflexivo, productor no sólo de significados sino también de sus propias "metaculturas" (Urban 2001); es decir "nociones en base a las que ciertos aspectos se naturalizan y definen como aculturales, mientras algunos se marcan como atributo particular de ciertos otros, o se enfatizan como propios, o incluso se desmarcan como generales o compartidos" (Briones 2005: 15) en la construcción de la recreación como representación cultural, a la vez que generan regímenes de verdad (Foucault y Gordon 1980) y formas de conocimiento específicas que sirven para reificar, naturalizar y perpetuar diferencias sociales, económicas e identitarias.

Para estudiar esta situación usamos una metodología multilocalizada (Marcus 1995) en diversas fiestas de recreación histórica caracterizadas por escenificar el enfrentamiento simbólico entre indígenas y romanos. Los eventos analizados en mayor profundidad y a los que nos remitiremos en este trabajo son las "Fiestas de Astures y Romanos" en Astorga, el festival "Guerras Cántabras" de Los Corrales de Buelna, y el "Festival Astur-Romano de La Carisa" en Carabanzo. Realizamos observación participante en hasta diez eventos desde 2002, con un análisis exhaustivo de cultura material en la edición de 2011 de Astorga y Los Corrales de Buelna, asumiendo las propuestas de hibridar metodologías arqueológicas y antropológicas (Castañeda 2008; Hamilakis 2011; Meskell 2005). Llevamos a cabo entrevistas semi-estructuradas y libres (King y Horrocks 2010) para recopilar los datos necesarios de múltiples actores: organizadores, visitantes, políticos locales y participantes, entre otros. Durante las entrevistas sacamos a colación los temas cruciales para nuestra investigación, a la vez que dejábamos espacio para la libre expresión de las opiniones de los entrevistados. También analizamos los discursos producidos durante los eventos dentro del programa de la recreación, centrándonos en su escenificación narrativa y corporal en contextos públicos, teniendo en cuenta además la vida cotidiana de los participantes: comportamiento informal y relación con la materialidad y los visitantes.

Nuestro trabajo revela las conexiones entre la expresión y representación social del pasado y los contextos empíricos de gestión arqueológica y patrimonial. En relación con esto, intentamos desvelar las vías de adquisición de conocimientos del público y sus reinterpretaciones del discurso académico (Moser 2001). Así, la recreación no es sólo entendida como fiesta o atracción turística, sino también como ejercicio de memoria colectiva donde se toman decisiones conscientes e inconscientes respecto a lo que es preservado o recordado y lo que es ignorado. Analizamos así cómo un determinado colectivo llega a seleccionar, recodificar y hacer circular ciertos objetos y significados del pasado y cómo estos se encuentran conectados con procesos contemporáneos. Estas elecciones son fundamentales para el modo en que los colectivos sociales emplean la memoria "de forma que suministre un pasado utilizable" (Wertsch 2002: 37). Así, el pasado puede convertirse en un recurso renovable (Harvey 2008) y apto para su utilización política en formas diversas: como un recurso en conflictos sobre la memoria (Zerubavel 2003), o como una representación que legitima y naturaliza el orden presente. Estos discursos pueden ser analizados porque la recreación representa abiertamente la "memoria cultural" de la comunidad, es decir, la comprensión colectiva del pasado asumida por la gente en un contexto histórico y social dado (Holtorf 2006). 
Como en otros contextos similares (Bauman y Sawin 1991), las relaciones de poder subyacentes en nuestro caso de estudio cobran sentido dentro del marco sociocultural amplio del que forman parte. Estas relaciones influyen en la "cultura histórica" del público, esto es, "las formas en las que el pasado es presentado en la vida cotidiana, de modo que se fomentan, promueven y guían las identidades colectivas que reflejan una consciente e inconsciente voluntad de recordar. (Harvey 2008: 21). Finalmente, nuestra investigación examina las formas en las que los actores locales se apropian de las representaciones del pasado de acuerdo a sus intereses, y cómo esta apropiación influye en las agendas arqueológicas y patrimoniales, a la vez que condiciona el papel que la sociedad atribuye a los arqueólogos.

\section{CULTURA MATERIAL Y CONSTRUCCIÓN DISCURSIVA DEL PASADO}

Durante nuestra participación y asistencia a los eventos hemos observado la existencia de ciertos patrones en la construcción material y discursiva de representaciones culturales de lo indígena. Los estudios exhaustivos realizados en las ediciones de 2011 de las recreaciones de Astorga y Los Corrales de Buelna muestran cómo la economía visual -que comprende la cultura material y las tecnologías del cuerpo (Foucault 1977) - y el conjunto de prácticas y discursos escenificados durante el festival, sirven para construir de modo performativo a los indígenas del siglo XXI. En cambio, el lado romano de estos eventos resultó ser menos interesante, al tratarse de un ensamblaje material y discursivo que se encuentra estandarizado a lo largo y ancho de Europa desde hace bastante tiempo (Appleby 2005).

La construcción social de lo indígena resulta mucho más interesante al tratarse de un proceso en eclosión. Este proceso de formación se encuentra desconectado del ámbito académico, siendo su construcción fundamentalmente parte de un movimiento popular que conecta con nuevos actores sociopolíticos y se adapta a un nuevo contexto cultural a distintas escalas. Nuestra investigación sugiere que este ensamblaje no se mantiene anclado a lo local, sino que converge con procesos similares a escala regional, nacional y europea. Así, esta construcción cultural de lo indígena puede ser definida como una "forma global": un conjunto de modelos ideales que organizan modos de comportamiento y razonamiento, y que poseen una "capacidad distintiva para descontextualizarse y recontextualizarse, abstraerse y moverse a través de distintas situaciones socioculturales [...] siendo capaces de adaptase a nuevos ambientes, codificando contextos y objetos heterogéneos" (Collier y Ong 2005: 11).

Este ensamblaje es replicado mediante procesos de mímica social que permiten conectar las distintas representaciones culturales de ámbito local. Así, las adaptaciones locales de este fenómeno presentan distintos grados de desarrollo en los diferentes casos de estudio: Los Corrales de Buelna expresa unos parámetros de representación más desarrollados y estabilizados, seguidos de Astorga y finalmente de Carabanzo, donde se replican contextos importados tanto de Los Corrales de Buelna como de Astorga. Estos fenómenos de imitación funcionan a través de prácticas sociales específicas. En particular, los grupos de personas más involucrados en la organización y realización de las fiestas participan y visitan asiduamente los eventos de recreación "hermanos". Así, obtienen ideas y comparten experiencias que después importan a sus 
propias recreaciones. Todos estos procesos de mímica social llevan a una homogeneización creciente de la forma y el contenido representados en estas recreaciones. Además, en los últimos años se ha producido un proceso de institucionalización de los eventos; así por ejemplo, las fiestas de Astorga, Los Corrales de Buelna y Lugo se han incorporado a la Asociación Española de Fiestas y Recreaciones Históricas, lo cual contribuye, entre otros factores, a la uniformización de prácticas, la creación de lazos formales entre los distintos grupos y al afianzamiento de su visibilidad pública (Fig. 2).
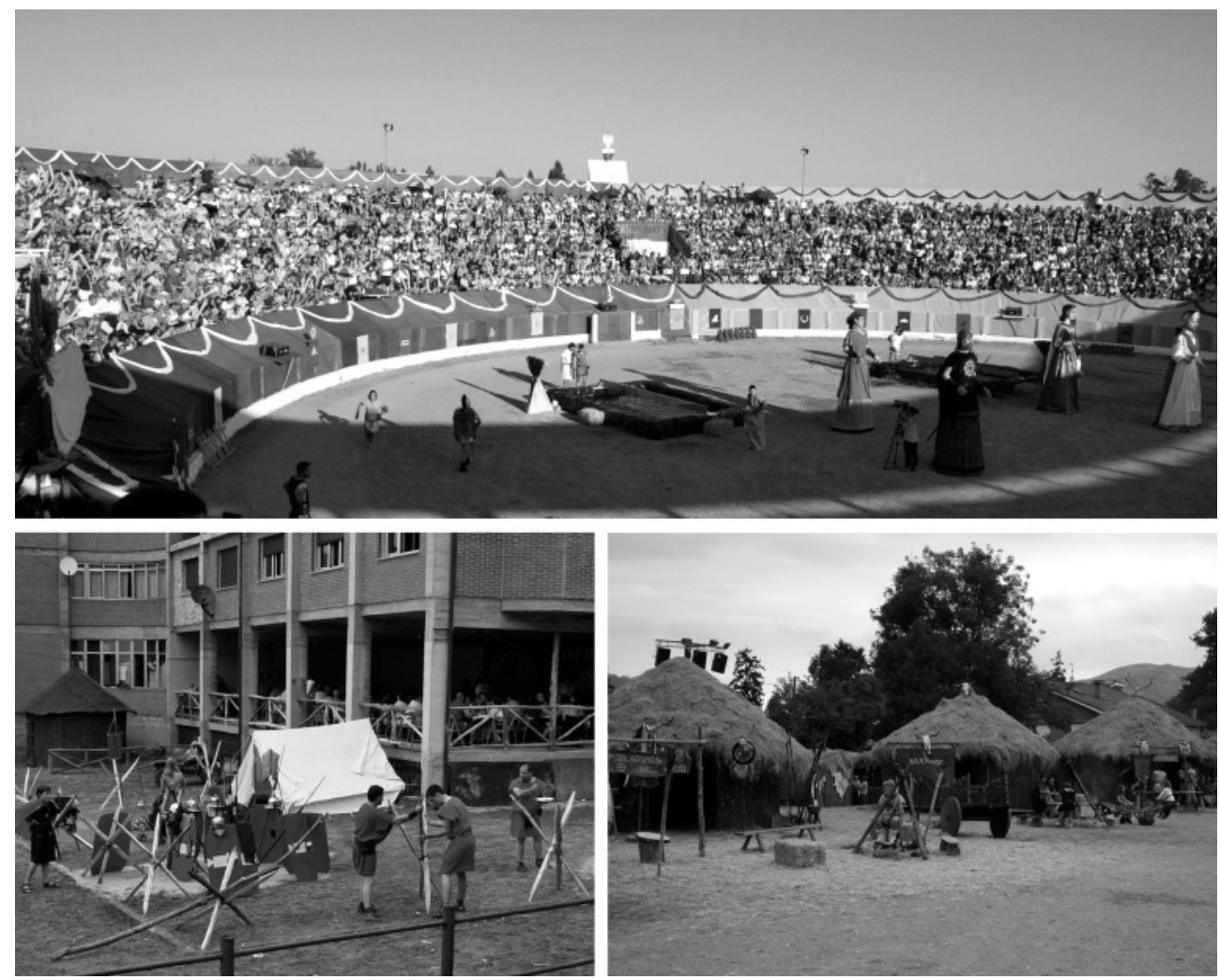

Figura 2.-Circo Romano en la edición de 2011 de la "Fiesta de Astures y Romanos de Astorga" (arriba). Tienda militar romana y cabaña astur, al fondo, en el "Festival Astur-Romano de La Carisa"de Carabanzo en 2011 (abajo, izquierda). Poblado cántabro en la edición de 2011 del festival "Guerras Cántabras" de Los Corrales de Buelna (abajo, derecha).

Con nuestra investigación hemos documentado etnográficamente y a través de estudios de cultura material la creación de una "forma global" emergente y hemos definido sus rasgos característicos. En lugar de realizar una descripción pormenorizada de los datos recabados, sintetizaremos a través de cuatro dimensiones fundamentales la esencia de la representación cultural de lo indígena en las recreaciones analizadas. 


\section{OTREDAD}

En primer lugar, la identidad de lo indígena prerromano se construye como un otro cultural. De manera dialéctica, lo indígena se convierte en una entidad opuesta a la identidad central y hegemónica representada por lo romano. Sin embargo, este hecho no implica el reconocimiento de la existencia de una perspectiva o subjetividad otra en los indígenas, de una alteridad epistemológica (Viveiros de Castro 2010). Más bien, la identidad de lo indígena se construye de forma relacional mediante el establecimiento de binarismos que se oponen a lo romano (Tabla 1), reproduciendo la dicotomía generalizada a nivel europeo, que enfrenta lo bárbaro a lo romano (Kristiansen 1996).

TABLA 1

\begin{tabular}{|c|c|}
\hline ASTURES/CÁNTABROS & ROMANOS \\
\hline barbarie & civilización \\
\hline primitivismo & modernidad \\
\hline nativos & foráneos \\
\hline natural & artificial \\
\hline organicidad & regularidad \\
\hline permanente & intermitente \\
\hline paz/armonía & violencia \\
\hline espontaneidad & rigidez \\
\hline suciedad & limpieza \\
\hline circular & cuadrangular \\
\hline irracional & racional \\
\hline
\end{tabular}

Quizás la situación en la que esta dicotomía resulta más evidente es la forma en que se construyen y organizan los poblados. Tanto el poblado astur astorgano como el asentamiento cántabro de Los Corrales de Buelna presentan una articulación orgánica, donde prevalece la heterogeneidad material y la construcción artesanal de cabañas circulares. Por su parte, los campamentos romanos presentan un ordenamiento racional y regular del espacio, con una homogeneidad material y formal de las construcciones de planta cuadrangular. Esta situación resultó evidente en nuestro estudio de la cultura material de la recreación de Astorga en 2011 (Fig. 3). La materialidad y la espacialidad del campamento enfatizan el carácter de lo romano como agente civilizador que representa progreso, orden y limpieza. Por el contrario, los poblados prerromanos transmiten una imagen idealizada de los indígenas como "bárbaros" que viven en comunión con la naturaleza y lo sobrenatural. 


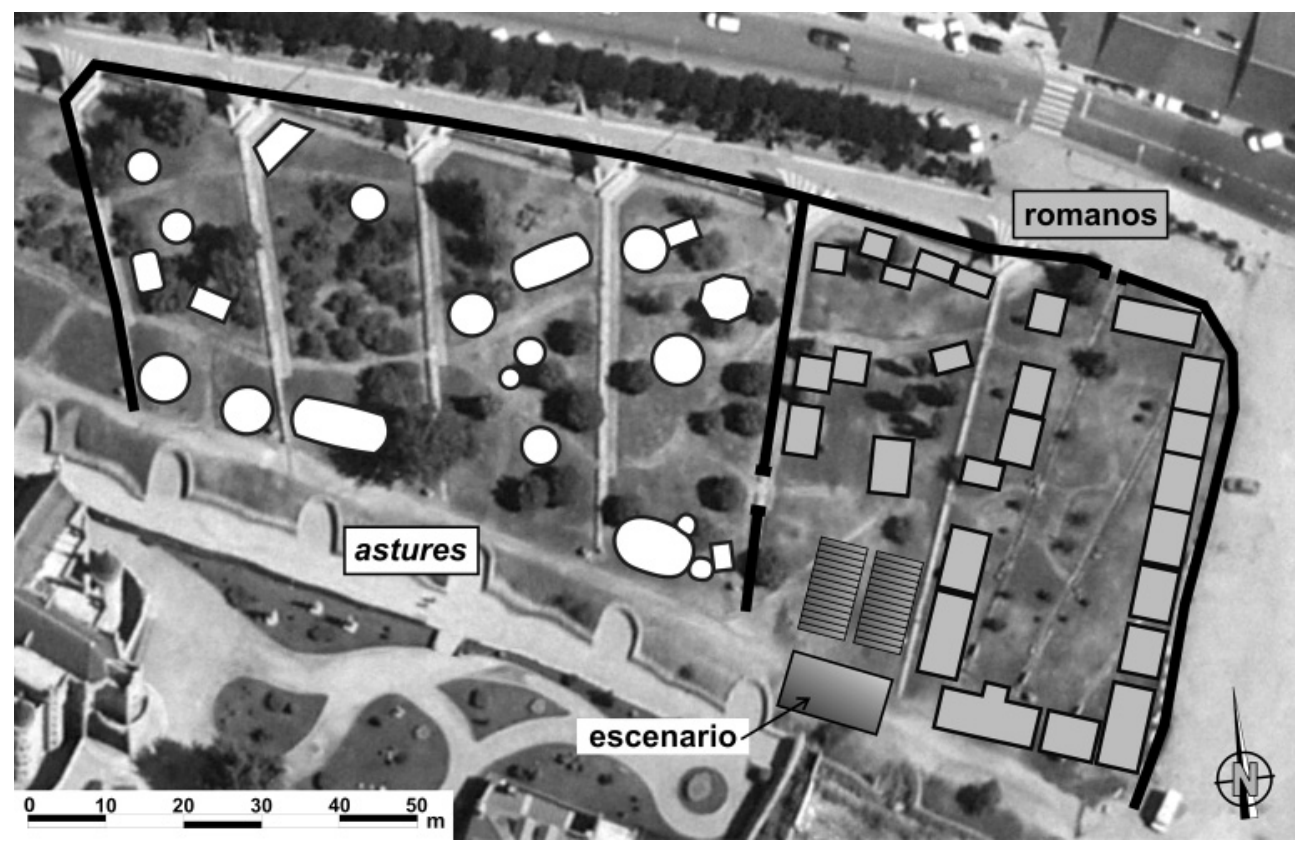

FIGURA 3.--Plano que muestra la organización del poblado astur y el campamento romano en la edición de 2011 de la "Fiesta de Astures y Romanos" de Astorga.

En este contexto, la dificultad de representar lo indígena obstaculiza el reconocimiento de un "paradigma otro" (Mignolo 2007). Esto lleva a la paradoja de que las formas de representación de lo indígena tienden a equipararse a las romanas y se construyen precisamente a partir sus categorías, que funcionan como una representación cultural ya consolidada en el imaginario popular. Esta contradicción concuerda con lo observado en Astorga, donde los guerreros astures portan espadas, mientras la presencia de lanzas es mucho menor, pese a ser el elemento más común en el registro arqueológico del entorno (Marín Suárez 2011a). Pese a la evidencia arqueológica, la representación de los astures se construye de forma convergente con la de los romanos y, así, en las escenificaciones de batallas, los astures pelean con espadas en lugar de lanzas. Igualmente, el sentido común lleva a que los regímenes de representación tiendan a equipararse. Así, en los actos sociales, los jefes tribales de Los Corrales de Buelna y el caudillo de los astures en Astorga han de presentarse y sentarse en igualdad de condiciones al César romano con un conjunto opuesto de tecnologías del cuerpo que refuerce la oposición binaria entre indígenas y romanos (Fig. 4). De este modo, los sujetos romanos vienen a representar modernidad y civilización mediante la representación exclusiva de personajes aristocráticos estereotipados, donde no aparecen campesinos, artesanos ni esclavos; por su parte, los indígenas se representan como colectivos orgánicos de escasa individualización (Hernando Gonzalo 2012: 65-84). Mientras el arquetipo romano es el "individuo", los indígenas subsumen su identidad en las tribus. A su vez, estas son concebidas como parte de un todo más amplio: el "pueblo astur", "el pueblo cántabro", cuya unidad socio-política se afirma durante las recreaciones. 

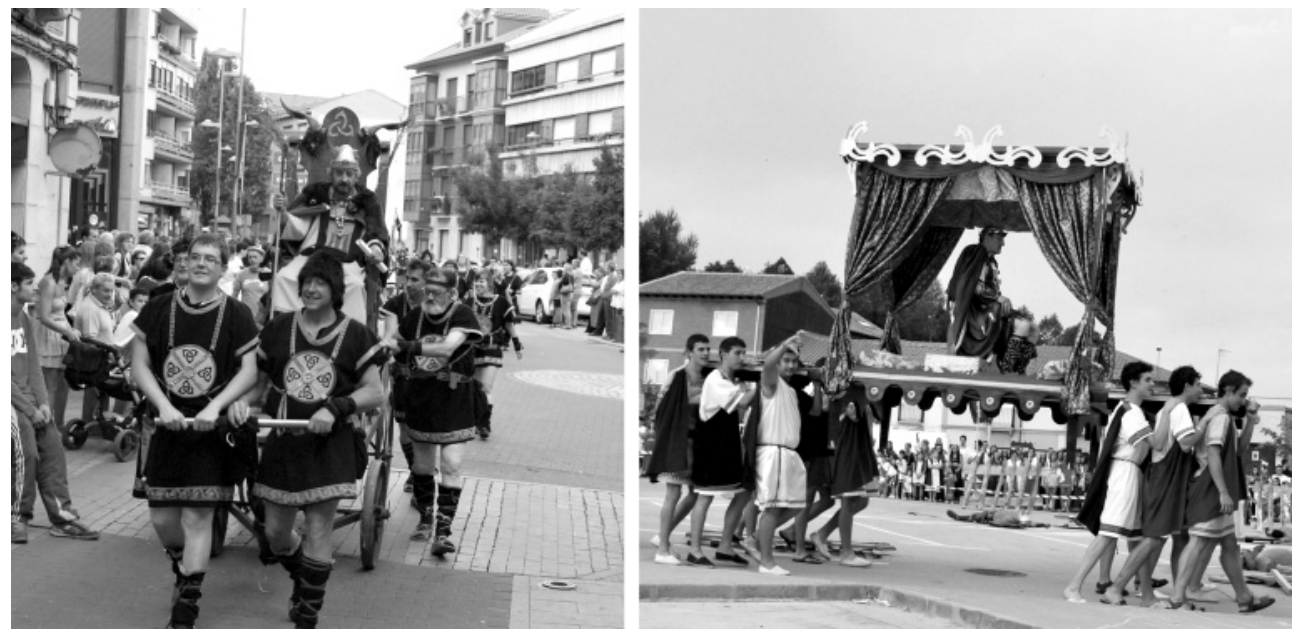

Figura 4.-Sebius, caudillo de los astures, en un pasacalle (izquierda). El César romano durante la escenificación de una batalla (derecha), en la edición de 2011 de la "Fiesta de Astures y Romanos" de Astorga.

En el aspecto discursivo, esta misma paradoja se refleja en el hecho de que las narrativas que refuerzan la construcción cultural de lo indígena cimentan su legitimidad en los textos de los autores latinos. Se trata de descripciones que responden a los intereses políticos del Imperio Romano y son asumidas acríticamente en las narraciones escenificadas en Carabanzo, Astorga y Los Corrales de Buelna. La prioridad dada a los textos clásicos sobre las investigaciones arqueológicas críticas es habitual en las interpretaciones sobre grupos de la Edad del Hierro en toda Europa; así por ejemplo, resulta lógico que en Astorga el caudillo Sebius gobierne el destino de todos los astures, complacientemente unificados bajo su mandato indiscutido. Por el contrario, los debates arqueológicos contemporáneos tienden a comprender el área como un complejo mosaico de pequeñas comunidades humanas con actitudes más bien aislacionistas y centradas en la vida interna del poblado, organizadas en grupos sociales de pequeña escala (González Ruibal 2011; Marín Suárez 2011a). Desde este punto de vista, el etiquetado de astures y cántabros como grupos étnicos unificados sólo surge y cobra sentido como una construcción cultural simplificada y derivada de las perspectivas etic de los autores romanos (Marín Suárez y González Álvarez 2011). En conclusión, la representación cultural de lo indígena se construye mediante la adopción acrítica de las descripciones romanas y no mediante la búsqueda de referentes directos de lo indígena aportados por la arqueología.

\section{PRESENTISMO Y ESENCIALISMO}

En la representación cultural realizada en las recreaciones, el "sentido común" del presente se proyecta hacia el pasado a través de las prácticas de los participantes. El presentismo busca en el pasado semejanzas que puedan conectarse con realidades 
presentes, para después generar continuidades históricas que permitan documentar la existencia de unos ciertos "orígenes" que legitiman la reproducción de procesos sociopolíticos contemporáneos (desigualdades de clase, poder, género, etc.). El presentismo desatiende la complejidad de los fenómenos privilegiando explicaciones esencialistas, aportando juicios sobre el pasado en lugar de explicaciones o interpretaciones históricas (Stocking Jr. 1965: 212) (Fig. 5). En consecuencia, la narración del pasado se llena de anacronismos y se reduce a una serie de binarismos fundacionales: buenos/malos, progreso/atraso, civilización/barbarie, etc. De este modo, los indígenas terminan por incorporar un conjunto de elementos derivados de un supuesto "sentido común", atribuyéndoles características como suciedad, informalidad, barbarismo, belicismo y amor por la naturaleza.

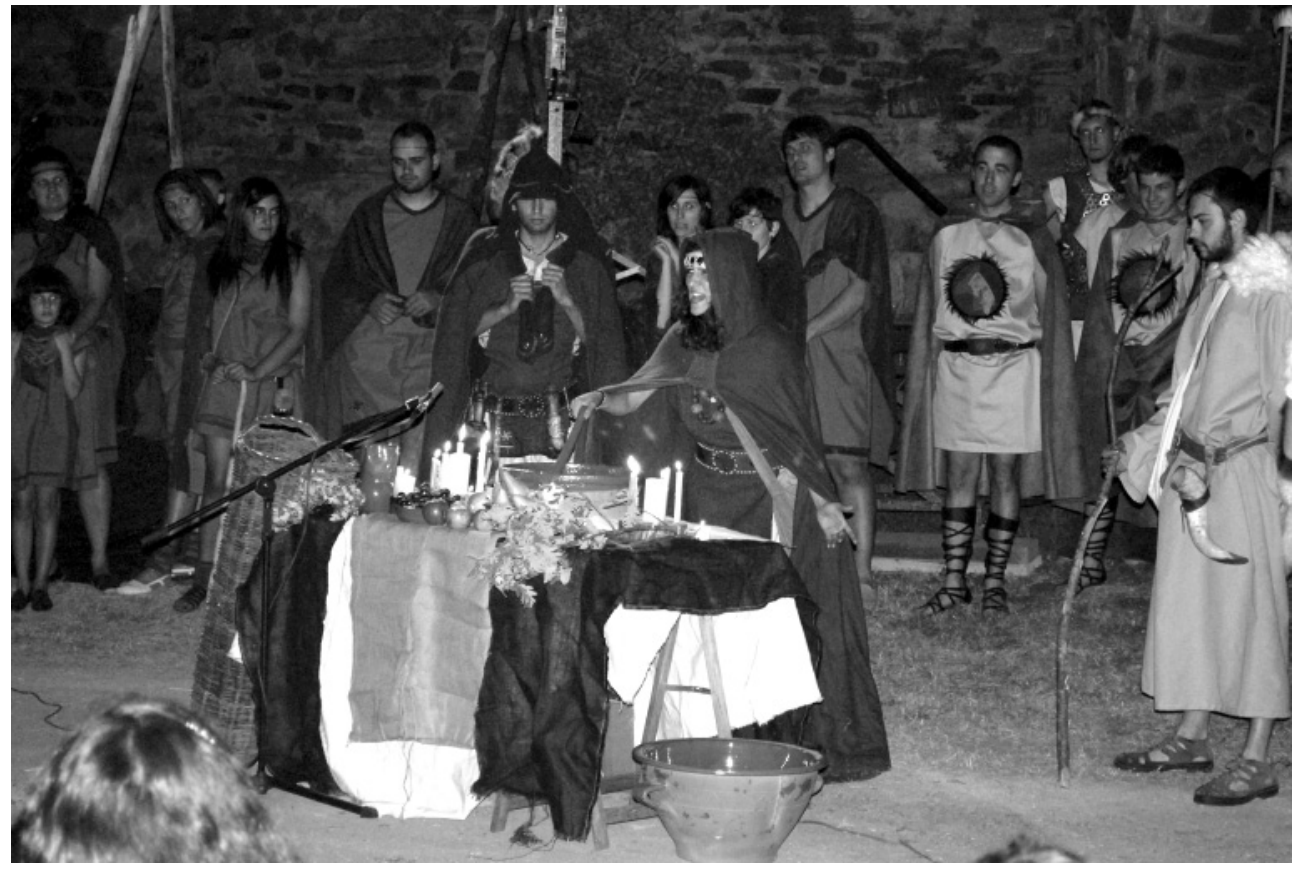

FiguRa 5.-Escenificación en la edición de 2011 de la "Fiesta de Astures y Romanos" de Astorga, en la que las tribus astures consultan a los dioses acerca de la idoneidad de ir a la guerra contra Roma. Para ello, elaboran una queimada y recitan un conjuro en gallego. En una región donde no se habla tal lengua, se recurre a esta tradición inventada que data de los años 1950 (González Reboredo 2001: 229-230) para establecer vínculos con un pasado atemporal cargado de magia y misterio. A la vez, es un ejemplo de cómo el regionalismo leonés incorpora elementos de discursos nacionalistas más desarrollados, como el gallego (ver Marín Suárez et al. 2012).

Así por ejemplo, la recreación astorgana se clausuró en 2011 con la incineración del guerrero Gausón, un personaje que no aparece en las fuentes clásicas y cuya primera mención fue realizada por el padre Carvallo (1695). Paradójicamente, la incineración no ha sido documentada arqueológicamente en el noroeste peninsular durante la Edad del Hierro; por tanto su escenificación sólo puede entenderse como una 
importación del "factoide celta" (James 1999). Más aún, según lo expuesto por el narrador del evento, este supuesto héroe prehistórico llevó a cabo gestas legendarias luchando contra Roma con la intención de pasar a la bistoria.

Resulta evidente cómo estos discursos proyectan al pasado prerromano roles sociales e ideas contemporáneas, naturalizándolas en el presente. El "sentido común" mediatiza el proceso por completo y filtra lo que es o no socialmente aceptable. Por otro lado, el carácter intrínsecamente esencialista del presentismo se refleja en las normas de rigor histórico establecidas en las recreaciones. Así, los organizadores promueven unas pautas y estándares en busca de la mayor autenticidad posible, alentando la no utilización de elementos contemporáneos como plástico, gafas de sol, relojes o mochilas ${ }^{2}$; sin embargo otras actitudes y elementos sin ningún tipo de base histórica o arqueológica son tolerados. Por ejemplo, es común en los tres casos observados que los indígenas usen cuernos animales para beber, que algunos estandartes de grupos romanos incluyan el Toro de Osborne o la bandera de España, y que grupos de indígenas tomen nombres derivados de la mitología nórdica. Esto es inconscientemente tolerado porque se ampara en el "sentido común" presentista y porque se vincula con las continuidades en las representaciones culturales de lo bárbaro a escala europea: vikingos, las "regiones célticas" como Gales, Bretaña o Escocia, la Irlanda medieval y lo celta en general. Todo amplificado por ficciones literarias y cinematográficas populares como Astérix y Obélix, Braveheart, la mitología nórdica y británica, El Señor de los Anillos, etc.

Presentismo y esencialismo se reflejan también en la naturalización del patriarcado y la representación del rol subalterno de la mujer. Entre los indígenas, las mujeres son guerreras no porque se reconozca la posible existencia de mujeres guerreras durante la Edad del Hierro, sino porque se ignora la separación de roles y de elementos que permitan su individualización. Se subsume la identidad femenina en una conceptualización genérica de lo indígena. Esto lleva a enfatizar la armonía interna de las comunidades prerromanas, evitando así lidiar con problemas complejos en la representación del género. Una situación similar se produce en relación a cuestiones de clase, pues no se representan actividades productivas ni en el ámbito indígena ni en los aristocráticos campamentos romanos.

\section{ESCASEZ DE PROFUNDIDAD GEOGRÁFICA Y TEMPORAL}

Diversos elementos de múltiples temporalidades históricas y ficticias se acoplan y superponen indiscriminadamente en las recreaciones. La concepción es atemporal: una simultaneidad de pasado y futuro en un presente difuso. Esto se evidencia en las cabañas de los poblados de Astorga y Los Corrales de Buelna. En su interior existe una multitud de elementos en exhibición que reflejan la falta de profundidad temporal y geográfica entre los participantes. Destacan altarcillos o pequeñas capillas utilizadas para exponer armas, plantas, cráneos de animales y figurillas de mitologías contemporáneas New Age basadas en el "mundo celta"; igualmente, se representan

\footnotetext{
${ }^{2}$ Por ejemplo, varios grupos romanos fueron multados por la comisión organizadora en 2011 en Astorga por utilizar sillas de plástico.
} 
petroglifos de la Edad del Bronce en cabañas de la Edad del Hierro. Lo importante es que este conjunto de elementos representan el "afuera" de lo romano, tanto a nivel geográfico -lo no aculturado- como cronológico -lo que está antes y lo que pervive después-. Resulta habitual la presencia de elementos propios de la cultura vernácula campesina como yugos o arados de madera preindustriales. Estas representaciones forman parte de la "invención de la tradición" (Hobsbawn y Ranger 1992) y enfatizan una conexión simbólica entre "nuestros ancestros" preindustriales y los pueblos prerromanos, considerados como los "habitantes originarios" del área. Esta idea de que la identidad de estos grupos permanece "latente" facilita el establecimiento de conexiones entre identidades prerromanas y sociedades vernáculas actuales, algo que autores como Caro Baroja realizaron indiscriminadamente (2003: 103). Se produce así una vinculación metafórica entre lo romano como "moderno" y lo indígena como "tradicional". Lo indígena simboliza la postura del postmoderno: un sujeto enraizado en lo local, conectado a la naturaleza y lo místico. Se enfrenta a la globalización y a lo moderno, representado simbólicamente por lo romano.

En Astorga, las cabañas se construyen con plantas circulares siguiendo modelos de reconstrucciones presentes en sitios arqueológicos musealizados próximos como El Chano (Peranzanes, León) (López Marcos et al. 2004), y de la arquitectura vernácula del área. Esto ejemplifica la desconexión entre el público y el conocimiento arqueológico: los participantes no tienen en cuenta los modelos de casas existentes en las excavaciones del área, mayoritariamente de planta cuadrangular (Sánchez-Palencia y Fernández-Posse 1986-1987). Esta contradicción deriva de la asunción generalizada de las imágenes sobre el pasado difundidas por la arqueología histórico-cultural (Marín Suárez 2011b), que ha uniformizado bajo la etiqueta de "Cultura Castreña" al conjunto cultural complejo y multidimensional de la Edad del Hierro del Noroeste Ibérico (Ayán Vila 2012a; González Ruibal 2011; Marín Suárez 2011a). La "Cultura Castreña" presenta como representaciones arquetípicas del periodo los castros con casas redondeadas al estilo de Coaña (Asturias) o Santa Tegra (Pontevedra). Estas narrativas son asumidas sin pasar filtro alguno por el público, que tiende a adoptar modelos simples y descartar narrativas complejas independientemente de su correspondencia con la realidad.

\section{REDUCCiÓN DE LA COMPLEJIDAD DEL PASADO}

La reducción de la complejidad del pasado recorre la totalidad de la materialidad y de las narraciones de las recreaciones analizadas. Esta situación deriva de la paradoja descrita por Lowenthal (citado en Harrison 2010: 25): cuanto más se esfuerzan las personas en conocer el pasado, más fácilmente lo remplazan por una versión mediatizada por su sentido común que se asemeja a su propia realidad. Así, las personas tienden a recrear el pasado de forma perfecta y deseable (Haraway 1989). Por ejemplo, el mundo romano es representado exclusivamente como una sociedad aristocrática dedicada a actividades ociosas o militares, mientras la complejidad indígena se simplifica mediante la aparición exclusiva de élites guerreras, carentes de diferenciación clara de roles y géneros. El sujeto arquetípico es el guerrero masculino, un modelo asumido indiscriminadamente por mujeres y niños. La adopción de un papel 
masculino y beligerante por parte de la mujer contribuye a la ocultación de las "actividades de mantenimiento" (González Marcén et al. 2008), minimizando la importancia de la mujer en la sociedad prerromana y naturalizando el patriarcado contemporáneo (Hernando Gonzalo 2005).

\section{PRÁCTICAS DE TRANSMISIÓN Y MEDIACIÓN DEL CONOCIMIENTO}

Nuestra investigación ha analizado las estrategias de construcción discursiva y de transmisión de conocimiento surgidas durante las recreaciones, en las que diversas fuentes de información convergen en la creación de narraciones y escenificaciones del pasado. Resulta evidente que los participantes otorgan un papel fundamental a los autores clásicos romanos, considerados en los tres casos de estudio como fuentes fidedignas de información cuyas narraciones deben ser representadas al pie de la letra. Las lecturas críticas de las fuentes realizadas desde ámbitos académicos, que señalan las motivaciones políticas subyacentes a los textos y la falta de correspondencia entre sus narrativas y el registro arqueológico (Marín Suárez y González Álvarez 2011; Menéndez Blanco et al. 2012; Salinas de Frías 1998) son ignoradas. Estas críticas subrayan el carácter etic de los autores romanos, sus simplificaciones interesadas y sus interpretaciones sesgadas en sus descripciones etnográficas de los indígenas, quienes son retratados, desde una perspectiva colonial, como bárbaros incivilizados.

En última instancia, la paradoja reside en el hecho de que las narrativas que afirman el carácter local de la identidad indígena (astur, cántabra, etc.) basan su legitimidad precisamente en los textos de los autores foráneos y coloniales romanos, aceptados acríticamente. La naturaleza de las fuentes clásicas se presta a este tipo de usos interesados debido a la vaguedad e imprecisión de sus referencias geográficas y descripciones narrativas; este carácter difuso abre la puerta a la reinterpretación y ampliación de sus contenidos. Así, pasajes de la Geografía de Estrabón usados para caracterizar a cántabros o astures pueden aplicarse a cualquier otro grupo bárbaro situado más allá de las fronteras del Imperio Romano. La ambigüedad conceptual e imprecisión de las categorías étnicas empleadas por los autores romanos estarían en la base de las generalizaciones panceltistas tan frecuentes a escala europea (Collis 2003). Mientras tanto, la arqueología se mantiene en un segundo plano como simple proveedora de objetos descontextualizados e iconografías varias. Tales elementos se exponen desordenadamente como "prerromanos" también bajo una difusa categoría única.

Por otra parte, para comprender los procesos de transmisión de conocimiento en las recreaciones resulta fundamental partir de una noción situada y múltiple del concepto de "público". Existen siempre muchos públicos, con distintos grados de implicación, motivación y participación (McManamon 1991). La mayor parte de ellos son sujetos para quienes el aspecto festivo de la recreación es el incentivo fundamental para participar. Sin embargo, ciertas personas se encuentran muy involucradas, no sólo en el evento, sino en lo que podemos denominar como "mundo de las recreaciones". Este es prácticamente un modo de vida que implica asistencia a otras recreaciones, organización y participación en eventos locales, mejora de los elementos decorativos personales y grupales, mantenimiento de blogs, etc. Estos expertos o líderes de cada grupo, que hemos denominado "sujetos bisagra", juegan un papel fundamental en la 
elaboración de la materialidad, las prácticas y los discursos de la fiesta. Funcionan como ejes nodales que conectan diversas fuentes de información sobre el pasado con la realidad de la recreación, mediando en las prácticas de conocimiento y transformando su forma y contenido. Juegan así un papel fundamental en la canalización del conocimiento e información que rodea y da sentido al evento que, a su vez, es transmitido, tanto al resto de participantes pasivos, como al público.

Los "sujetos bisagra" suelen ser hombres que durante las recreaciones utilizan estrategias de diferenciación, como la acumulación de elementos de estatus simbólico: armas, joyería, prendas valiosas o cuernos en brazos y casco, etc. Sebius, líder de la tribu ambacta y caudillo de todos los astures en la recreación de Astorga, incorpora un barroco ensamblaje de marcadores simbólicos: casco dorado con cuernos, pendientes y brazaletes de metal, espada de antenas al cinto, pieles, trisqueles impresos en ropa y armas, y un báculo tipo signum equitum celtibérico, como los documentados en la cabecera del río Duero a cientos de kilómetros de Astorga (Lorrio 2010). Los "sujetos bisagra" eran considerados como los "expertos", los conocedores de cada grupo a los que sus compañeros nos referían para contestar nuestras preguntas diciendo: "ese es el que sabe". Al contrario de la situación descrita por Crang (1996), los expertos localizados en nuestros casos de estudio no se encuentran amparados por investigadores académicos.

Esta indefinición generalizada facilita la incorporación de múltiples elementos discursivos y materiales de distintas procedencias que acaban constituyendo la espina dorsal de las narraciones y la cultura material de las recreaciones. Internet se ha convertido en una fuente y medio crucial para la difusión de información. En particular, las narraciones pseudocientíficas abundan y circulan descontroladamente en la Red, siendo discutidas, expandidas y transformadas de forma constante en distintos foros $^{3}$. La naturaleza de Internet imposibilita la filtración o validación de las informaciones que circulan, de modo que estas cobran vida propia y acaban por ser plasmadas y reproducidas durante las recreaciones.

No obstante, al desarrollar los discursos escenificados, los "sujetos bisagra" también se basan en informaciones procedentes de museos y sitios arqueológicos musealizados. De este modo, los "sujetos bisagra" introducen una forma de "ruido" en su proceso de mediación, materializando sus propias construcciones derivadas de la hibridación de múltiples fuentes de información: Internet, museos, "sentido común" presentista, pseudoarqueología, libros de divulgación, etc. En cualquier caso, este es uno de los escasos vectores a través de los cuales el conocimiento académico, tras múltiples mediaciones, llega al público. Por ejemplo, el castro musealizado de El Chano sirvió a algunos de estos "sujetos bisagra" como fuente de inspiración para el diseño de sus propias cabañas y vestidos en Astorga (Fig. 6). Por supuesto, este conocimiento sufre una traslación geográfica sin ningún tipo de mediación cultural o adaptación al ámbito local: las casas de El Chano son redondas, y así se construyen en Astorga pese a que, como dijimos antes, la arqueología demuestra la prevalencia de la planta cuadrangular en el entorno de la ciudad.

\footnotetext{
3 Cabe destacar ejemplos como el clausurado -pero aún accesible- Celtiberia (http:// www.celtiberia.net Acceso 15 noviembre 2012) y otros espacios en funcionamiento como Terrae Antiquae (http://terraeantiqvae.com/ Acceso 15 noviembre 2012) o Arqueólogos, Red Española de Historia y Arqueologia (http://www.historiayarqueologia.com/ Acceso 15 noviembre 2012).
} 

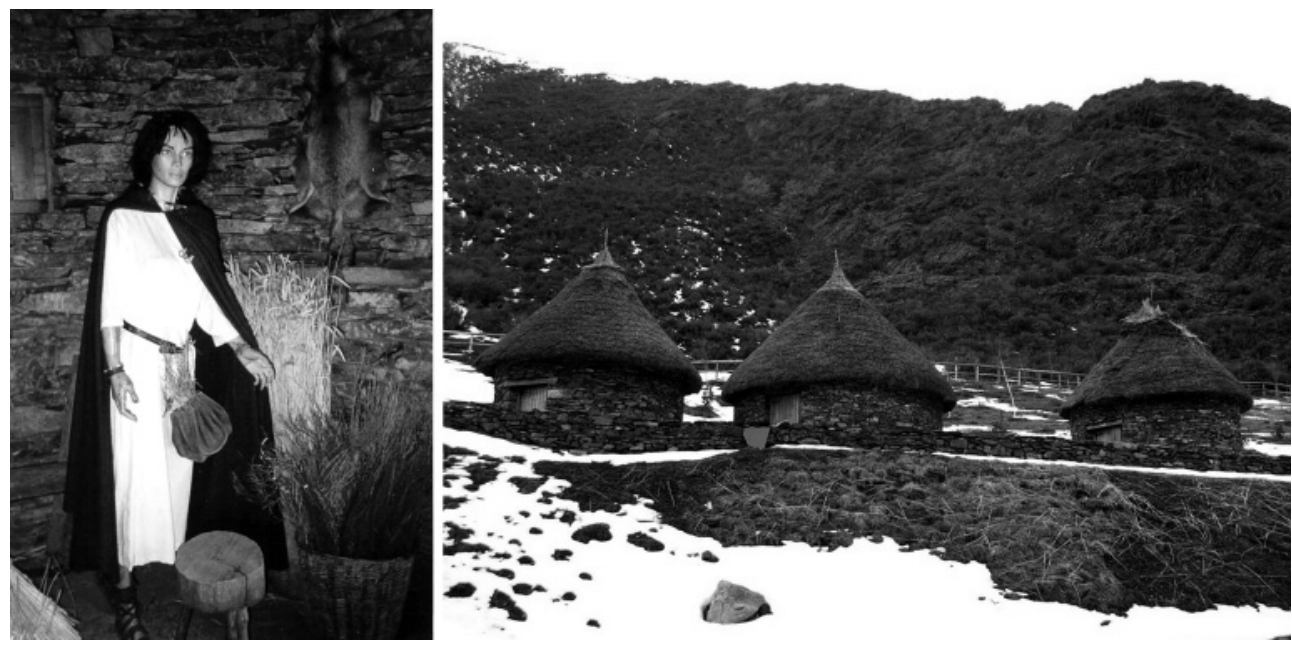

Figura 6.- Maniquí castreño en el interior de una de las cabañas de El Chano (Peranzanes, León) (Ayán Vila 2012a: 835) que serviría de modelo para la vestimenta empleada, entre otros, por la tribu de los guigurros de Astorga (izquierda). Réplicas de cabañas prerromanas situadas a los pies del castro de El Chano (Ayán Vila 2012a: 845) (derecha).

En conclusión, en lugar de acusar a los participantes por sus reinterpretaciones e inexactitudes, presuponiendo su ignorancia, deberíamos mirar al patio trasero de la arqueología y sus problemas (Andrews 2010). De hecho, la presencia de investigadores en este tipo de eventos y en las esferas donde los contenidos expuestos y escenificados en las recreaciones son producidos y debatidos -Wikipedia, blogs, fórums, revistas de difusión, etc.- resulta marginal en España, así como el reflejo de las investigaciones críticas más recientes. ¿Cuáles son las razones para esta incomparecencia académica?

Por una parte, creemos que las fiestas de recreación histórica pueden suscitar cierto temor entre los investigadores consolidados, pues estos contextos de socialización y construcción del pasado "desde abajo" abonan el campo para un hipotético cuestionamiento de la posición dominante del investigador, que en otros espacios sociales se encuentra fuera de discusión. Esta incomparecencia de los investigadores académicos se comprende mejor si consideramos que la participación activa en eventos públicos o la producción de contenidos para la difusión no conlleva un incremento del "capital simbólico-académico" del investigador (Bourdieu 2008). En España la carrera académica está pautada por instituciones de evaluación y prospectiva, cuyos parámetros de calidad sólo marginalmente consideran aspectos relacionados con la participación pública, la difusión o la transferencia de conocimiento.

Igualmente, los académicos se enfrentan a la dificultad de transmitir significados complejos, mientras la simplicidad de los discursos histórico-culturales y pseudoarqueológicos es fácilmente asumida y reinterpretada con jovialidad por el público general. En este sentido, es relevante señalar cómo la producción académica tradicional, basada en el paradigma histórico-cultural y con esquemas positivistas, se encuentra fácilmente disponible para el público en librerías, bibliotecas públicas e 
Internet. Por el contrario, la investigación crítica desarrollada desde finales de los años 90 no se encuentra accesible para el público general. Esto se debe, en parte, a la deriva actual del sistema editorial del ámbito científico. La tendencia a privatizar los resultados de la investigación histórica/arqueológica es creciente, debido al auge de las empresas editoriales que limitan su acceso a unas pocas instituciones de investigación que pueden abordar los altísimos precios de suscripción a las revistas especializadas. De este modo, el público general pierde la oportunidad de acceder a estos textos, independientemente de que las investigaciones hayan sido sufragadas con sus propios impuestos.

A la luz de todo lo dicho, ¿podría decirse que la arqueología puede ser considerada socialmente útil en España? Probablemente la respuesta de un ciudadano medio será negativa. En nuestra opinión, esta situación socava la legitimidad de la disciplina a la hora de reclamar un mayor acceso a financiación y apoyo institucional, e incluso amenaza su supervivencia a largo plazo. La ausencia de arqueólogos en la esfera pública abre la puerta a la apropiación generalizada del pasado que subyace a las agendas regionalistas y nacionalistas contemporáneas. Así, el pasado es consciente e inconscientemente utilizado para naturalizar desigualdades, jerarquías y opresiones que reproducen ideologías contemporáneas de clase y género, o relacionadas con el sujeto, como el individualismo.

\section{LAS RECREACIONES HISTÓRICAS Y LA CONSTRUCCIÓN DE IDENTIDADES AUTO- NÓMICAS}

Más allá de factores de índole económica o turística, las recreaciones históricas no pueden sustraerse de ciertas dinámicas identitarias que se encuentran en proceso de construcción en el área geográfica estudiada, en particular en relación con el auge de los discursos nacionalistas y regionalistas.

Tras el franquismo, el Estado español adoptó una articulación administrativa descentralizada en la que distintas competencias y esferas de poder fueron cedidas progresivamente por el Estado central a instituciones regionales: las Comunidades Autónomas (CCAA). Este nuevo escenario propició el resurgimiento de procesos de construcción identitaria vinculados a nacionalidades "históricas" (Linz 1981), que se legitiman a través de la "invención de la tradiciones" (Hobsbawn y Ranger 1992). Estas operaciones conjugan la búsqueda de "ancestros" con la proyección hacia el pasado más distante de identidades y territorialidades contemporáneas para reforzar la agenda política de los actores sociopolíticos nacionalistas/regionalistas. Se generan así discursos históricos de construcción nacional equiparables a una mitología que puede funcionar como una guía para el presente (Malinowski 1954), como una forma de dar cuenta y difuminar las contradicciones sociales, según Lévi-Strauss (ver discusión en Leach 1985: 57-58), o como una explicación de los orígenes de la sociedad (Eliade 1954).

En este sentido, la historia y la arqueología son los arsenales que proveen de munición simbólica y material para tales discursos. Especialmente, las comunidades prerromanas son protagonistas destacadas de los mitos fundacionales sobre los primeros habitantes del solar ibérico (Ruiz Zapatero 2006). El público general conoce los nombres de estas gentes gracias a los autores clásicos que también ofrecen so- 
meras y simplistas descripciones etnográficas, todo lo cual contribuye a reforzar la familiaridad y proximidad de estos grupos de la Edad del Hierro (Hill 1989). A su vez, la resistencia de estos grupos indígenas frente al invasor romano, perfectamente escenificada en las recreaciones históricas analizadas, es un fácil recurso que exalta los valores con los que el nacionalismo/regionalismo asturiano, cántabro o leonés se vincula simbólicamente. Como en cualquier narración mitológica, personajes estereotipados representan cosmovisiones integrales. Así, el "indígena" escenificaría una representación cultural del guerrero local enraizado en la tierra y en equilibrio con la naturaleza -como Astérix, Braveheart, o los guerreros astures y cántabros- que lucha contra un "otro" hegemónico -los romanos o las identidades hegemónicas contemporáneas: española, castellana, etc.-. Estas narrativas, cuyos excesos y abusos han sido ya analizados para el área que nos concierne (Díaz Santana 2002; García Sánchez 2009; González Morales 1994; Marín Suárez 2005), sirven como proveedores de alteridad para las identidades locales en su búsqueda por distinguirse respecto a las identidades centrales (Briones 2005). Estas operaciones evidencian la relevancia de los usos prospectivos del patrimonio, ya que "toda memoria es siempre memoria para algo" (Geary 1995: 12, cursiva en el original).

En los ejemplos de nuestro caso de estudio, pueden detectarse tensiones en dos ámbitos fundamentales. Por un lado, en CCAA como Asturias o Cantabria, algunos agentes nacionalistas tratan de sustentar sus ideologías políticas a través de la vinculación de su discurso con identidades pretéritas de astures o cántabros, de cara al fortalecimiento de su otredad frente a la identidad central española. No resulta difícil establecer puentes de unión entre estos discursos políticos y las recreaciones históricas analizadas, donde se escenifican los enfrentamientos que tendrían lugar entre unos "pueblos" indígenas libres -astures, cántabros- que se enfrentan valerosamente a una potencia central e imperial -Roma-. Así, el auge de estos eventos no puede desligarse de la creciente relevancia social y cultural que los discursos nacionalistas/regionalistas contemporáneos están adquiriendo en regiones como Cantabria, Asturias o León. Por ello, no debe resultarnos extraño que en el "Festival Astur-Romano de La Carisa" los actos de recreación histórica se complementen con "etnocomercio" (Comaroff y Comaroff 2009) y actuaciones de grupos de música folk y "celta", que normalmente sustentan y se identifican con el "asturianismo" cultural y político, y que tales conciertos incluyan gritos en favor de la independencia asturiana. Tampoco es casual que el festival "Guerras Cántabras" de Los Corrales de Buelna cuente con Miguel Ángel Revilla -fundador de la Asociación para la Defensa de los Intereses de Cantabria ${ }^{4}$, líder desde 1988 del Partido Regionalista de Cantabria y presidente del Gobierno de Cantabria entre 2003 y 2011- entre sus habituales. Este político participaba activamente como miembro de la tribu de los coniscos, si bien en las últimas ediciones asiste tan sólo como espectador 5 .

En el caso astorgano, la fricción identitaria se produce a otra escala político-administrativa: entre la provincia de León -o el "País Leonés" (León, Zamora y Salamanca)

\footnotetext{
${ }^{4}$ Página web: http://www.adic-cantabria.org/ (Acceso 5 noviembre 2012).

5 Pax romana en Cantabria, El Diario Montañés (7 de septiembre de 2009) http:// www.eldiariomontanes.es/20090907/sociedad/guia-para-salir/romana-cantabria-20090907.html (Acceso 8 noviembre 2012).
} 
y la CCAA de Castilla y León. Esta extensa construcción autonómica, con capital en Valladolid, integró el territorio leonés al no recibir éste un estatuto de autonomía propio. Tal decisión política generó un descontento entre una parte de la ciudadanía leonesa que aumentó a partir de los años 1990, debido a la percepción social de que los intereses de León estaban siendo abiertamente subordinados a los de Valladolid. Este marco de confrontación política e identitaria sentó las bases para el crecimiento del "Leonesismo", como corriente cultural y política (Díez Llamas 1992). Este movimiento se aglutinaría en torno al partido Unión del Pueblo Leónes (UPL), que perseguía la segregación del "País Leonés" de Castilla. Emulando los exitosos dispositivos desplegados por movimientos nacionalistas/regionalistas análogos en las vecinas Galicia o Asturias, los actores sociopolíticos leonesistas buscaron la legitimidad de sus reclamaciones en referentes pretéritos como el medieval Reino de León o los prerromanos astures. Esta última retórica identitaria basa su fuerza evocadora en la resistencia de este grupo indígena frente al invasor romano. La identidad de los astures permanecería así en una suerte de estado latente pese a su derrota histórica, aprovechando y reproduciendo así las tradicionales tesis indigenistas (Barbero y Vigil 1978)-. Al potenciar la ligazón de lo leonés con los astures se alude también a la diversidad identitaria presente en Castilla y León, poblada a la llegada de los romanos por distintas formaciones culturales que fueron nombradas como pueblos: vacceos, celtíberos, vettones... Una vez más, la historia y la arqueología facilitarían la construcción social de unos distantes "ancestros" que reproducirían culturalmente la alteridad identitaria leonesa frente a la castellana.

La recreación de Astorga sirve de escenario en el que estudiar las relaciones entre el auge de los discursos nacionalistas/regionalistas y las fiestas de recreación histórica ambientadas en las guerras entre indígenas y romanos. Pero, a la vez, centramos nuestro interés en las conexiones sociales y políticas de esta celebración a escala local, desvelando algunas consecuencias prácticas en aspectos como la gestión del patrimonio o la función social de los arqueólogos.

En Astorga, ciudad que remonta sus orígenes al término de las Guerras Cántabras como campamento militar romano (Mañanes 1983-1984), el ascenso de la UPL en la esfera política municipal coincidió con el origen de las "Fiestas de Astures y Romanos". Con el auge de este evento, los astures comenzaron a ser tomados como una referencia cultural legítima para la ciudadanía, en alternativa a la identidad romana de la ciudad que había monopolizado hasta entonces los discursos oficiales promovidos por las instituciones locales. No en vano, el acceso de la UPL al gobierno local a partir de 2003 condujo al replanteamiento de la política de patrimonialización exclusiva del pasado romano de la ciudad que imperaba hasta entonces. Nació así el proyecto de excavación del castro de La Mesa en Castrillo de los Polvazares, localidad perteneciente al municipio de Astorga. Esta aspiración fue una de las condiciones exigidas por la UPL para apoyar al PSOE en su candidatura a la alcaldía del Ayuntamiento (Almanza 2006). La excavación arqueológica fue encargada a una empresa privada sin establecer unas preguntas o líneas previas de investigación. Pese a que estudios precedentes atribuían una cronología romana para este castro (Orejas 1996), el grupo leonesista afirmaba -antes incluso del comienzo de las excavaciones- que se trataba de un yacimiento de los astures. En paralelo, planteaban "la creación de un centro de interpretación de la cultura astur" (Almanza 2005) que, para Enrique Soto 
-teniente alcalde y concejal de UPL- serviría "para que conozcamos mejor nuestras raíces y cómo el mundo astur, los castros y sus habitantes, se fueron integrando paulatinamente en el mundo romano, sin que hubiera sustitución de una población por otra [...] los astures conservaron las costumbres que pudieron preservar, y esa continuidad llega hasta nuestros días" (Almanza 2006).

Así pues, el carácter latente de la identidad y cultura de los astures -nunca completamente derrotados- juegan en Astorga un papel fundamental en la definición de políticas culturales sufragadas con fondos públicos. Tal situación tiene consecuencias en cuanto al papel desempeñado por la arqueología como disciplina y los arqueólogos como profesionales al servicio de la sociedad. La arqueología se convierte así en una práctica subsidiaria vinculada a agendas políticas determinadas. En ese horizonte, los arqueólogos son considerados como meros "Operarios" -en palabras de Enrique Soto (Fernández 2008)- que cumplen con un guión preestablecido por directrices políticas.

Así, en Astorga lo astur comenzó a ser utilizado como referente identitario con el que reforzar la alteridad leonesa frente al discurso centralista desplegado por Valladolid. Gradualmente, la carga política de la recreación disminuyó a medida que el peso social y político de la UPL descendía, convirtiéndose en un evento básicamente lúdico. A partir de ahí, podemos concluir que las fiestas de recreación histórica pueden desempeñar un papel significativo en la negociación y reproducción cultural de discursos identitarios en contextos políticos donde ideologías nacionalistas o regionalistas juegan un papel fundamental en relación con el desarrollo del Estado autonómico español.

\section{CONCLUSIONES}

A partir de un análisis etnográfico y de cultura material, nuestra investigación muestra cómo las recreaciones históricas no son simples eventos recreativos que responden a intereses económicos, sino que en ellas convergen una multiplicidad de procesos sociopolíticos y económicos que no sólo reflejan relaciones de poder e ideologías contemporáneas, sino que también las reconfiguran. Estos eventos son representativos del giro social emocional/afectivo (Agnew 2007), que se caracteriza por una tendencia a la representación intuitiva del pasado basada en el sentido común, la preponderancia de la experiencia personal cotidiana sobre los hechos y procesos históricos, y un pensamiento temporal simplificado y superficial. Estas características impregnan las recreaciones, siendo adoptadas, negociadas y reproducidas por la ciudadanía al margen de la academia. Este proceso no es inocuo, sino que se conecta con cuestiones políticas de inclusión y exclusión identitaria, gobernabilidad, y la organización activa del poder. En particular, las recreaciones históricas analizadas se relacionan estrechamente con las tensiones identitarias que surgen en paralelo a la construcción de la España autonómica.

Estas construcciones son habituales en procesos de articulación de Estados no centralistas donde las regiones generan formas locales de alteridad para especificarse en relación a la "identidad central" (Briones 2005). A la vez, cristalizan en narrativas históricas que compiten entre ellas para tornarse "oficiales". Estas historias oficiales son 
teleológicas y generan una imagen lineal del pasado donde prima la evolución causal y cronológica de los eventos a partir de una "causa originaria" (Martin-Jones 2006): lo astur, lo cántabro, etc. Consideramos que una arqueología crítica permite deconstruir los discursos que utilizan el pasado para legitimar agendas políticas presentes. La arqueología debería partir del presente para remontarse hacia atrás en el tiempo y desvelar las múltiples imágenes del pasado cuya "verdad" debe ser críticamente examinada, mostrando que el desarrollo histórico es contingente, variable y discontinuo.

Nuestro trabajo revela cómo la proyección hacia el pasado de desigualdades contemporáneas de género, etnia o clase las naturaliza en el presente, haciendo más difícil su superación. Por ello, la arqueología debería ofrecer y presentar referentes de alteridad geográfica, cultural y temporal en la esfera pública, en lugar de perpetuar la búsqueda de "ancestros" (Whitley 2002). Entender las formas en las que el conocimiento se produce, negocia y circula en las recreaciones históricas nos permite actuar como agentes críticos que trabajan en la desestabilización y complejización de los discursos conservadores predominantes, a la vez que innovar el corpus teóricometodológico disciplinar (Zaera-Polo 2008: 76). Por otro lado, las dificultades observadas en el acceso del público a recientes publicaciones críticas que cuestionan las interpretaciones más tradicionales, han de superarse mediante una apuesta firme de los investigadores por el Open Access (Suber 2012) y otras formas de comunicación. Además de llevar a cabo proyectos de Arqueología Pública en sitios arqueológicos (Ayán Vila 2012b), sería exigible que demostrásemos un mayor compromiso participando activamente en espacios horizontales como las recreaciones, donde el gran interés por el pasado demostrado por la ciudadanía no debería dejarnos indiferentes. La potenciación de estas iniciativas de difusión y transferencia de conocimiento sería efectiva probablemente de recibir estímulos como su reconocimiento y valoración por parte de los organismos de evaluación de la actividad científica.

Somos conscientes de que el análisis de las recreaciones y la revelación de sus ideologías subyacentes resulta inútil si no se establecen programas activos que estrechen la distancia existente entre academia y público. Las "percepciones de muchos" (Holtorf 2005: 8) tienen consecuencias no sólo en cuanto a la consideración social del arqueólogo o las formas de gestión patrimonial y arqueológica, sino también para la disciplina arqueológica como tal. En definitiva, si nuestro trabajo no es valorado socialmente, ¿por qué seguir financiándolo con fondos públicos?

\section{BIBLIOGRAFÍA CITADA}

Agnew, V. 2007. "History's affective turn: Historical reenactment and its work in the present". Rethinking History 11 (3): 299-312.

Almansa Sánchez, J. 2011. "Arqueología para todos los públicos. Hacia una definición de la Arqueología Pública "a la española"». ArqueoWeb 13: 87-107. Accesible en: http://www.ucm.es/info/ arqueoweb/pdf/13/almansa.pdf

Almanza, M. 2005. "Recuperar el castro de La Mesa de Castrillo costará 280.000 euros". Diario de León 19/08/2005.

Almanza, M. 2006. "La musealización del castro recibe una aportación de 57.000 euros'". Diario de León 21/01/2006.

Andrews, C. 2010. Community uses of maritime heritage in Bermuda: a heritage ethnography with museum implications. University of Cambridge: Tesis doctoral inédita. 
Appleby, G. 2005. "Crossing the Rubicon: fact or fiction in Roman re-enactment". Public Archaeology 4 (4): 257-265.

Ayán Vila, X. M. 2012a. Casa, Familia y Comunidad en la Edad del Hierro del NW. Universidade de Santiago de Compostela: Tesis doctoral inédita.

Ayán Vila, X. M. 2012b. "Public archaeology, democracy and community Experiences from Iron Age hillforts at Galicia (Spain)", en Schücker, N. (ed.), Integrating Archaeology Science-Wish-Reality. International Conference on the Social Role, Possibilities and Perspectives of Classical Studies. Papers beld in Frankfurt a. M. on 12-14 June 2012: 41-47. Frankfurt: Römisch-Germanische Kommission, Frankfurt A.M. des Deutschen Archäologischen Instituts.

Barbero, A. y Vigil, M. 1978. La formación del feudalismo en la Península Ibérica. Barcelona: Crítica.

Bauman, R. y Sawin, P. 1991. "The politics of participation in folklife festivals", en B. KirshenblattGimblett, B.; Karp, I y Lavine, S. D. (eds.), Exhibiting cultures: The poetics and politics of museum display: 288-314. Washington D.C.: Smithsonian Institution Press

Bogard, W. 1998. "Sense and Segmentarity: Some Markers of a Deleuzian-Guattarian Sociology". Sociological theory 16 (1): 52-74.

Bourdieu, P. 2008. Homo Academicus. Madrid: Siglo XXI.

Briones, C. 2005. "Formaciones de alteridad: contextos globales, procesos nacionales y provinciales", en Briones, C. (ed.), Cartografias argentinas: politicas indigenas y formaciones provinciales de alteridad: 9-40. Buenos Aires: Antropofagia.

Brisset Martín, D. E. 1997. "Proceso evolutivo de los rituales de conquista en España". Revista de Dialectología y Tradiciones Populares 52 (1): 65-104.

Brisset Martín, D. E. 2001. "Fiestas hispanas de moros y cristianos. Historia y significados". Gazeta de Antropología 17: artículo 03. Accesible en http://hdl.handle.net/10481/7433

Burillo Mozota, F. 2005. Segeda (Mara - Belmonte de Gracián). La ciudad celtibérica que cambió el calendario. Zaragoza: Fundación Segeda.

Caro Baroja, J. 2003. Los pueblos de España, 2. Madrid: Alianza.

Carvallo, L. A. 1695. Antigüedades y cosas memorables del Principado de Asturias. Madrid: Imprenta de Julián de Paredes.

Castañeda, Q. 2008. "The 'Ethnographic Turn' in Archaeology. Research Positioning and Reflexivity in Ethnographic Archaeologies", en Castañeda, Q y Matthews, C. N. (eds.), Ethnographic Archaeologies. Reflections on Stakebolders and Archaeological Practices: 25-61. Plymouth: AltaMira Press.

Colomer, L. 2002. "Educational facilities in archaeological reconstructions. Is an image worth more than a thousand words?". Public Archaeology 2 (2): 85-94.

Collier, S. J. y Ong, A. 2005. "Global assemblages, anthropological problems", en Ong, A. y Collier, S. J. (eds.), Global assemblages: technology, politics, and ethics as anthropological problems: 321. Malden: Blackwell.

Collis, J. R. 2003. The Celts. Origins, Myths and Inventions. Stroud: Tempus.

Comaroff, J. L. y Comaroff, J. 2009. Ethnicity, Inc. Chicago: The University of Chicago Press.

Cook, A. 2004. "The use and abuse of historical reenactment: thoughts on recent trends in public history". Criticism 46 (3): 487-496.

Crang, M. 1996. "Magic Kingdom or a Quixotic quest for Authenticity?". Annals of Tourism Research 23 (2): 415-431.

Díaz-Andreu, M. 1993. "Theory and Ideology in Archaeology: Spanish Archaeology under the Franco régime". Antiquity 67 (254): 74-82.

Díaz-Andreu, M. 1995. "Archaeology and Nationalism in Spain", en Kohl, P. L. y Fawcett, C. (eds.), Nationalism, Politics, and the Practice of Archaeology: 39-56. Cambridge: Cambridge University Press.

Díaz-Andreu, M. 2003. "Arqueología y dictaduras: Italia, Alemania y Francia", en Wulff Alonso, F. y Álvarez Martí-Aguilar, M. (eds.), Antigüedad y Franquismo (1936-1975): 33-73. Málaga: CEDMA.

Díaz Santana, B. 2002. Los celtas en Galicia: arqueología y política en la creación de la identidad gallega. Noia: Tosoxoutos.

Díez Llamas, D. 1992. La identidad leonesa. León: Diputación Provincial de León, Instituto Leonés de Cultura. 
Eliade, M. 1954. The Myth of the Eternal Return. Nueva York: Pantheon Books.

Fernández, M. 2008. "La Diputación dedica 74.000 euros a estudiar el castro de La Mesa. La institución provincial inició la segunda fase de excavación de los restos". Diario de León 5/09/2008.

Foucault, M. 1977. Discipline and Punish. The Birth of the Prision. Nueva York: Pantheon Books.

Foucault, M. y Gordon, C. 1980. Power/Knowledge: Selected Interviews and Other Writings 1972-1977. Nueva York: Pantheon Books.

Gapps, S. 2003. "Authenticity Matters; Historical Re-enactment and Australian Attitudes to the Past". Australian Cultural History 23: 105-116.

García Canclini, N. 1982. Las culturas populares en el capitalismo. México: Nueva Imagen.

García Sánchez, J. 2009. "El uso político de objetos arqueológicos: las estelas gigantes de Cantabria". Saldvie 9: 249-263.

Geary, P. 1995. Phantoms of Remembrance: Memory and Oblivion at the End of the First Millennium. Princeton: Princeton University Press.

Geertz, C. 1997. "Cultural tourism: tradition, identity and heritage construction", en Nuryanti, W. (ed.), Tourism and Heritage Management: 14-24. Yogyakarta: Gadjah Mada University.

González Marcén, P.; Montón Subías, S. y Picazo Gurina, M. 2008. "Towards an Archaeology of Maintenance Activities", en Montón Subías, S. y Sánchez Romero, M. (eds.), Engendering Social Dynamics: The Archaeology of Maintenance Activities: 3-8. Oxford: Archaeopress, BAR International Series 1862.

González Morales, M. R. 1994. "Justificando las raíces: política y arqueología en la España autonómica". Arqcrítica 8: 8-10.

González Reboredo, X. M. 2001. "A construción de referentes de identidade etno-nacional. Algunhas mostras sobre Galicia” en González Reboredo, X. M. (ed.), Etnicidade e Nacionalismo. Simposio Internacional de Antropoloxía: 201-247. Santiago de Compostela: Consello da Cultura Gallega.

González Ruibal, A. 2011. "The Politics of Identity: Ethnicity and the Economy of Power in Iron Age Northern Iberia", en Cifani, G. y Stoddart, S. (eds.), Landscape, Ethnicity and Identity in the Archaic Mediterranean Area: 245-266. Oxford: Oxbow Books.

Hall, P. A. 2007. "The Dilemmas of Contemporary Social Science». Boundary 234 (3): 121-141.

Hamilakis, Y. 2011. "Archaeological Ethnography: A Multitemporal Meeting Ground for Archaeology and Anthropology". Annual Review of Anthropology 40: 399-414.

Haraway, D.J. 1989. Primate Visions. Nueva York: Routledge.

Harrison, R. 2010. "What is Heritage?", en Harrison, R. (ed.), Understanding the Politics of Heritage: 5-42. Manchester: Manchester University Press, Open University.

Harvey, D.C. 2008. "The history of heritage", en Graham, B. y Howard, P. (eds.), The Ashgate Research Companion to Heritage and Identity: 19-36. Aldershot: Ashgate.

Hernando Gonzalo, A. 2005. "¿Por qué la Historia no ha valorado las actividades de mantenimiento?", en González Marcén, P.; Montón Subías, S. y Picazo Gurina, M. (eds.), Dones i activitats de manteniment en temps de canvi: 115-133. Barcelona: Centre d'Estudis del Patrimoni Arqueològic de la Prehistòria, Universitat Autònoma de Barcelona, Treballs d'Arqueologia, 11.

Hernando Gonzalo, A. 2012. La fantasía de la individualidad. Sobre la construcción sociohistórica del sujeto moderno. Buenos Aires: Katz.

Hill, J. D. 1989. "Re-thinking the Iron Age". Scottish Archeological Review 6: 16-24.

Hobsbawn, E. J. y Ranger, T. O. 1992. The Invention of Tradition. Cambridge: Cambridge University Press.

Holtorf, C. 2005. From Stonehenge to Las Vegas. Archaeology as Popular Culture. Walnut Creek: Altamira Press.

Holtorf, C. 2006. The Monumental Past. Toronto: University of Toronto Press.

James, S. 1999. The Atlantic Celts. Ancient People or Modern Invention? Londres: British Museum Press.

Jimeno Martínez, A. 2000. "Numancia: pasado vivido, pasado sentido". Trabajos de Prebistoria 57 (2): 175-194.

King, N. y Horrocks, C. 2010. Interviews in Qualitative Research. Londres: Sage.

Kristiansen, K. 1996. "European origins - 'civilisation' and 'barbarism'”, en Graves-Brown, P.; Jones, S. y Gamble, C. (eds.), Cultural Identity and Archaeology. The Construction of European Communities: 138-144. Londres: Routledge. 
Leach, E.R. 1985. Lévi-Strauss. Londres: Fontana Press.

Linz, J. J. 1981. "La crisis del Estado unitario, nacionalismos periféricos y regionalismo", en AA. VV, La España de las Autonomias (pasado, presente y futuro): 651-752. Madrid: Espasa-Calpe.

López Marcos, M. A.; López González, L. F. y Álvarez González, Y. 2004. "La recuperación de un yacimiento: el castro de Chano (Peranzanes, León)", en Val Recio, J. y Escribano Velasco, C. (eds.), Puesta en valor del Patrimonio Arqueológico en Castilla y León. Salamanca: Junta de Castilla y León.

Lorrio, A. J. 2010. "Los signa eqvitum celtibéricos: origen y distribución". Palaeohispanica 10: 427446.

Malinowski, B. 1954. Magic, Science and Religion: and other essays. Garden City: Doubleday.

Mañanes, T. 1983-1984. "Asturica Augusta: la ciudad y su entorno". Portugalia 4-5: 215-229.

Marcus, G. E. 1995. "Ethnography in/of the World System: The Emergence of Multi-sited Ethnography". Annual Review of Anthropology 24: 95-117.

Marín Suárez, C. 2005. Astures y asturianos. Historiografía de la Edad del Hierro en Asturias. Noia: Toxosoutos.

Marín Suárez, C. 2011a. De nómadas a castreños. Arqueología del primer milenio antes de la era en el sector centro-occidental cantábrico. Universidad Complutense de Madrid: Tesis doctoral inédita.

Marín Suárez, C. 2011b. "La Edad del Hierro en el occidente cantábrico: de la cultura arqueológica al grupo arqueológico". Férvedes 7: 123-132.

Marín Suárez, C. y González Álvarez, D. 2011. "La romanización del Occidente Cantábrico: de la violencia física a la violencia simbólica”. Férvedes 7: 197-206.

Marín Suárez, C., González Álvarez, D. y Alonso González, P. 2012. "Building Nations in the XXI Century. Celticism, Nationalism and Archaeology in Northern Spain: the case of Asturias and León". Archaeological Review from Cambridge 27 (2): 11-31.

Martin-Jones, D. 2006. Deleuze, Cinema and National Identity. Narrative Time in National Contexts. Edimburgo: Edinburgh University Press.

McManamon, F. P. 1991. "The Many Publics for Archaeology". American Antiquity 56 (1): 121-130.

Menéndez Blanco, A., Jiménez Chaparro, J. I., González Álvarez, D. y Álvarez Martínez, V. 2012. "La conquista romana del Occidente Cantábrico: novedades arqueológicas", en Cascalheira, J. y Gonçalves, C. (eds.), Actas das IV Jornadas de Jovens em Investigação Arqueológica - JIA 2011, Vol. II: 339-346. Faro: Universidade do Algarve, Promontoria Monográfica 16.

Merriman, N. (ed.). 2004. Public Archaeology. Londres: Routledge.

Meskell, L. 2005. "Archaeological Ethnography: Conversations around Kruger National Park". Archaeologies: Journal of the World Archaeological Congress 1 (1): 81-100.

Meskell, L. 2012. The Nature of Heritage: The New South Africa. Malden: Wiley-Blackwell.

Mignolo, W. D. 2007. "Introduction". Cultural Studies 21 (2-3): 155-167.

Miller, D. (ed.). 1998. Material cultures: Why some things matter. Londres: UCL Press.

Moser, S. 2001. "Archaeological Representation. The Visual Conventions for Constructing Knowledge about the Past", en Hodder, I. (ed.), Archaeological Theory Today: 262-283. Cambridge: Polity Press.

Moshenska, G. 2009. "What is Public Archaeology?". Present Pasts 1: 46-48.

Orejas, A. 1996. Estructura social y territorio: el impacto romano en la cuenca noroccidental del Duero. Madrid: CSIC.

Pena Castro, M. J. 2004. "El negocio de la historia en la Feria Medieval de Noia". Sociológica. Revista de pensamiento social 5: 81-100.

Peralta Labrador, E. 2009. "Las Guerras Cántabras", en Almagro Gorbea, M. (ed.), Historia Militar de España. Prebistoria y Antigüedad: 247-265. Madrid: Laberinto.

Rojas Rabaneda, A. 2011. "Herramientas y estrategias de difusión del Patrimonio Histórico: los eventos de recreación histórica en Cataluña". e-rph: Revista electrónica de Patrimonio Histórico 9. Accesible en: http://www.revistadepatrimonio.es/descarga.php?nombre_documento=revistas/numero9/difusion/estudios/pdf/difusion-estudios.pdf

Rowlands, M. J., y De Jong, F. 2007. "Reconsidering Heritage and Memory", en De Jong, F. y Rowlands, M. J. (eds.), Reclaiming Heritage. Alternative Imaginaries of Memory in West Africa. Studies in Cultural Heritage: 13-28. Walnut Creek: Left Coast Press. 
Ruiz Zapatero, G. 2003. "Historiografía y "Uso Público" de los celtas en la España Franquista", en Wulff Alonso, F. y Álvarez Martí-Aguilar, M. (eds.), Antigüedad y Franquismo (1936-1975): 217240. Málaga: CEDMA.

Ruiz Zapatero, G. 2005. "Soria, "Keltiberoi" - 2004: ¡la historia a la calle!". Complutum 16: 279-286.

Ruiz Zapatero, G. 2006. "The Celts in Spain. From Archaeology to Modern Identities", en Rieckhoff, S. (ed.), Celtes et Gaulois, l'Archéologie face à l'Histoire, I: Celtes et Gaulois dans l'histoire, l'historiographie et l'idéologie moderne. Actes de la table ronde de Leipzig, 16-17 juin 2005: 197218. Glux-en-Glenne: Bibracte, Centre archeologique européen.

Rullani, E. 2006. Economia della conoscenza. Creatività e valore nel capitalismo delle reti. Roma: Carocci.

Salinas de Frías, M. 1998. "La guerra de los cántabros y astures, la etnografía de España y la propaganda de Augusto", en Hidalgo, M. J.; Pérez, D. y Gervás, M. J. R. (eds.), "Romanización" y "reconquista" en la Península Ibérica: nuevas perspectivas: 155-170. Salamanca: Ediciones Universidad de Salamanca.

Salinas de Frías, M. 2011. "Las fuentes clásicas y el poblamiento prerromano del occidente peninsular. Problemas de etnicidad y cultura", en Ruiz Zapatero, G. y Álvarez Sanchís, J. R. (eds.), Castros $y$ Verracos. Las gentes de la Edad del Hierro en el occidente de Iberia (Reunión Internacional Castros y Verracos. Ávila 9-11 de noviembre de 2004, Palacio de los Serrano): 129-157. Ávila: Diputación de Ávila.

Sánchez-Palencia, F. J., y Fernández-Posse, M. D. 1986-1987. "Vivienda y urbanismo en la Asturias interior: La Corona de Corporales". Zephyrus 39-40: 375-386.

Sánchez Carretero, C. y Ortiz García, C. 2008. «Rethinking ethnology in the Spanish context». Ethnologia Europaea 38 (1): 23-28.

Schadla-Hall, T. 1999. "Editorial: Public Archaeology". European Journal of Archaeology 2 (2): 147158.

Schulten, A. 1943. Los cántabros y astures y su guerra con Roma. Madrid: Espasa-Calpe.

Stocking Jr., G. W. 1965. "On the limits of 'presentism' and 'historicism' in the historiography of the behavioral sciences". Journal of the History of the Behavioral Sciences 1(3): 211-218.

Suber, P. 2012. Open Access Overview. Focusing on open access to peer-reviewed research articles and their preprints. Accesible en: http://www.earlham.edu/ peters/fos/overview.htm

Tejerizo García, C. 2012. "Identidad nacional y arqueología en el primer franquismo: Julio Martínez Santa-Olalla y la arqueología de época visigoda", en Aldea Celada, J. M.; Ortega Martínez, P.; Pérez Miranda, I. y Reyes de Soto García, M. D. (eds.), Historia, Identidad y Alteridad. Actas del III Congreso Interdisciplinar de Jóvenes Historiadores: 479-502. Salamanca: AJHIS, Colección Temas y Perspectivas de la Historia, 2.

Thrift, N. 2006. "Re-inventing invention: new tendencies in capitalist commodification". Economy and Society 35(2): 279-306.

Urban, G. 2001. Metaculture: how culture moves through the world. Minneapolis: University of Minnesota Press.

Viejo-Rose, D. 2011. Reconstructing Spain: Cultural Heritage and Memory after Civil War. Brighton: Sussex Academic Press.

Viveiros de Castro, E. 2010. Metafísicas caníbales. Lineas de antropología posestructural. Buenos Aires: Katz.

Wertsch, J.V. 2002. Voices of collective remembering. Cambridge: Cambridge University Press.

Whitley, J. 2002. "Too many ancestors". Antiquity 76 (291): 119-126.

Zaera-Polo, A. 2008. "The Politics of the Envelope. A Political Critique of Materialism". Volume 17: 76-105.

Zerubavel, E. 2003. Time Maps: Collective Memory and the Social Shape of the Past. Chicago: University of Chicago Press.

Fecha de recepción: 19 de noviembre de 2012

Fecha de aceptación: 17 de junio de 2013 